\title{
CONCEPÇÕES SOBRE A AFETIVIDADE NO AMBIENTE EDUCACIONAL
}

\author{
Elizete Santiago dos Santos ${ }^{1}$ \\ Rosana Rego de Almeida ${ }^{2}$
}

\begin{abstract}
Resumo
Este artigo apresenta algumas abordagens sobre a afetividade no ambiente educacional. A intenção é discutir afetividade e aprendizagem na visão de alguns pensadores que discutem sobre a temática. Considerando a complexidade da temática, não há intenção de esgotar a discussão, pois a amplitude da problemática educacional está diretamente ligada a questão existencial. A afetividade precisa ter seu espaço garantido no ambiente escolar, trabalhando a autoestima e fazendo desta uma grande aliada para acreditar em si, alicerça seu aprendizado na confiança e tem garantido positivo seu objetivo. No processo de aprendizagem, o sujeito encontra-se associado às várias estruturas teóricas exemplificadas pela epistemologia, e em todas se observa a presença de questões de ordem emocional interferindo direta ou indiretamente. Como metodologia foi realizada a pesquisa bibliográfica, tendo como arcabouço alguns teóricos para embasar esta reflexão. Conclui-se, com este trabalho, que a vivência de uma afetividade saudável entre professor e aluno corrobora com o processo educativo, ajuda no trabalho didático pedagógico do professor e facilita a aprendizagem e a formação da personalidade dos alunos inseridos no Ensino Fundamental.
\end{abstract}

Palavras-chave: Educação. Afetividade. Aprendizagem.

\begin{abstract}
This article presents some approaches on affectivity in the educational environment. The intention is to discuss affectivity and learning in the view of some thinkers who discuss the theme. Considering the complexity of the theme, there is no intention to exhaust the discussion, since the breadth of the educational problem is directly linked to the existential issue. Affectivity needs to have its space guaranteed in the school environment, working on self-esteem and making this a great ally to believe in you, bases your learning on trust and has guaranteed your objective positive. In the learning process, the subject is associated with the various theoretical structures exemplified by epistemology, and in all of them the presence of emotional issues is directly or indirectly interfering. As a methodology, bibliographic research was carried out, having as a framework some theorists to support this reflection. It is concluded, with this work, that the experience of a healthy affectivity between teacher and student corroborates with the educational process, helps in the pedagogical didactic work of the teacher and facilitates the learning and the formation of the personality of the students inserted in the Elementary School.
\end{abstract}

Keywords: Education. Affectivity. Learning.

\section{Conceito de Afetividade}

A história da educação afetiva relata uma caminhada através da motivação para o efetivo aprendizado, sabe-se que "o que" motiva o aluno a aprender é também

\footnotetext{
1 Mestra em Ciências da Educação pela Faculdade Interamericana de Ciências Sociais - FICS; Especialista em Docência do Ensino Superior pela Dom Pedro ;Especialista em Gestão Escolar pela Castelo Branco; Graduada em Historia pela FACIBA; Graduada em Pedagogia pela UNEB; Bacharel em Filosofia e Teologia pelo IUCH. Email: eli.zetesantiago@hotmail.

2 Mestra em Ciências da Educação pela Faculdade Interamericana de Ciências Sociais - FICS; Pós graduada em Psicopedagogia, Pós graduada em Educação Infantil pela CESAP; Licenciada em Pedagogia pela UNIFACS; Docente no Colégio Costa Pinto em Dias D'Ávila. Email: rosanafpedagogia@gmail.com
} 
a relação que esse aluno tem com o professor. Como essa motivação pode ser provocada e usada, até o ponto de vista do processo de aprendizagem.

A Afetividade por sua vez, pode ser classificada com diferentes aspectos dentre elas a Psicologia, a Pedagogia e a Filosofia. Nesse contexto, a afetividade é representada na perspectiva da pedagogia, tendo em vista a relação educativa que se estabelece entre o educador e o educando em sala de aula. É na sala de aula que o professor se apodera de suas emoções e inclui ou exclui o aluno de forma tão sutil que muitas vezes não se percebe.

A título de ilustração podemos pensar que o termo Pedagogo/Pedagogia, através da história da educação, evidencia-se aquele que conduz "pega" pela mão e conduz ao saber. Na literatura atual, atribui-se ao educador, ao professor, o título de mediador do conhecimento.

O estado emocional do professor também deve ser levado em conta quando se estabelece que o educador esteja sempre pronto para atender o aluno demonstrando firmeza e equilíbrio emocional como se o único a ser envolvido nas relações emocionais fosse o aluno.

Nesse caso, faz-se necessário que se estabeleça uma relação de harmonia entre professor- aluno; aluno- professor e aluno-aluno esses conceitos são atribuídos devido à atenção que é impulsionada pela elocução dos sentimentos, das emoções e desenvolve-se por meio da formação do sujeito. A benevolência é a parte do nosso psíquico responsável pelo medo de sentir e analisar a realidade (ARROYO, 2000).

\section{Abordagem Sobre Fatores Afetivos Para Alguns Teóricos da Educação}

De acordo com alguns teóricos da educação há vários fatores afetivos que se apresentam na relação professor aluno e esses fatores impactam diretamente no processo de aprendizagem.

Wallon (1978) entende que a primeira relação do ser humano ao nascer é com o ambiente social, ou seja, com pessoas ao seu redor. Contudo, é fundamental entender que no decorrer do processo de construção do aprendizado os vínculos afetivos vão se ampliando e a figura do professor passa a ser de grande importância na relação do aprendizado. 
Partindo desse contexto entende-se que para aprender são necessários dois atores, o que ensina e o que aprende, contudo, existe um vínculo se estabelece entre ambos, sinalizando, portanto, que a aprendizagem está completamente influenciada pelos fatores afetivos.

Vygotsky (2002) defende que a afetividade se manifesta na relação professor aluno e constitui elementos inseparáveis do processo de construção do conhecimento. Além disso, a qualidade da interação pedagógica vai conferir um sentido afetivo para o objeto de conhecimento a partir das experiências. A qualidade do diálogo pedagógica confere um sentido afetivo para se adquira o conhecimento a partir das experiências vivenciadas pelos estudantes.

Jean Piaget (1968) foi um dos primeiros autores que questionou as teorias sobre a afetividade e a cognição como aspectos funcionais separados, elucidando inclusive que a afetividade não está resumida apenas às emoções e aos sentimentos, mas abarca também a vontade e as tendências do ser humano, como ele cita abaixo:

Os aspectos afetivos, sociais e cognitivos da conduta são, de fato, indissociáveis, a afetividade constitui a energética das condutas cujas estruturas correspondem às funções cognitivas e, se a energética não explica a estruturação nem o inverso, nenhuma poderia funcionar sem a outra (lbid., p. 104).

Diante dessa concepção, percebe-se que não é possível explicar a inteligência pela afetividade e nem a afetividade pela inteligência. Entretanto, segundo Piaget (1995) elas são inseparáveis, pois defende-se que toda ação e pensamento comportam um aspecto cognitivo, representado pelas estruturas mentais, e um aspecto afetivo, representado por uma energética, que é a afetividade, torna-se um meio de controle e reforço da desigualdade social apesar de não ser o propósito dos educadores.

De acordo com os teóricos existem vários fatores afetivos que se apresentam na relação professor aluno e esses fatores tem impactos diretos no processo de aprendizagem. Mesmo sabendo que o quesito afetividade durante muito tempo ficou esquecido nas instituições de ensino pode-se dizer que:

Os laços entre alunos e professor se estreitam na imensa proximidade desse imprescindível afeto, torna-se importante descobrir ações, estratégias, procedimentos, sistemas e reflexões integrados que estabeleçam veículos fortes entre aluno professor e aprendizado (ANTUNES, 2007, p.12). 
Nesta contemporaneidade educacional é extremamente importante que os professores percebam que a afetividade é tão importante na vida do educando quanto as questões cognitivas pois, as mesmas vão se desenvolvendo ao longo do processo da construção da formação do estudante.

Wallon (1999) destaca em seus estudos que a inteligência não é o elemento mais importante do desenvolvimento humano, mas esse desenvolvimento depende de três vertentes: a motora, a afetiva e a cognitiva. Assim, a dimensão biológica e social era indissociável porque se completam mutuamente.

Corroborando com Wallon (Ibidem, 1999) o estudante que não está emocionalmente bem mesmo sendo inteligente não vai desenvolver-se bem pois o processo de aprendizagem se dá concomitante com o estado emocional.

A serenidade e a paciência do educador, mesmo em situações difíceis, fazem parte da paz que a criança necessita. Para que o aluno conquiste a sua autonomia, segundo Piaget (1975) ela precisa ter a oportunidade de usufruir das relações sociais de cooperação. As relações de coerção embotam o desenvolvimento, roubando à criança e ao adulto a possibilidade de se emanciparem intelectual, moral e afetivamente. Somente as relações sociais podem permitir o livre intercâmbio dos pontos de vista da autonomia.

Na perspectiva genética de Wallon, o ser humano é organismo antes de ser psiquismo, por isso este estudioso afirma que "a maturação orgânica é indispensável para a evolução funcional. Ela deposita nesta, a cada vez, possibilidades que se acrescentam ao material anterior e que não podem ser extraídas dele como um simples efeito de seus mecanismos intrínsecos" (WALLON, 2008, p. 119).

Vale a pena lembrar que para este autor a emoção, o ato motor, e a inteligência constituem campos funcionais que no início da vida da criança são indiferenciados e imaturos. No entanto, Wallon vai admitir que, ao longo do desenvolvimento humano existem fases em que predominam o afetivo e fases em que predominam a inteligência.

É preciso ressaltar a importância das questões afetivas, uma vez que estas podem desencadear comportamentos positivos ou negativos por parte do sujeito. Existem condições internas e externas para a aprendizagem, principalmente quando 
se fala em estudantes com dificuldades na aprendizagem. Logo, a visão questionadora que procura perceber a relação entre educadores e educandos no que concerne à afetividade e conhecimento que vem contribui de forma grandiosa com a sociedade.

Sabe-se que os alunos sempre foram preparados para alcançar o sucesso, nunca os professores se preocuparam em prepará-los para a decepção até porque para alguns professores os bons alunos são aqueles que tiram notas boas. Dentro da sala de aula professores e alunos parecem estranhos não existe uma convivência afetuosa e sadia.

Nossos alunos estão se transformando em verdadeiras máquinas de aprender, de decorar conteúdos os quais são esquecidos. É diante desse paradigma que a educação se torna fria alheia aos afetos sem prazer; com isso estamos apenas informando e não formando pessoas.

Entende-se que a afetividade dentro do contexto da sociabilidade do sistema educacional pode ser classificada em várias linhas de pensamento como na Psicologia, na Sociologia e na Pedagogia. Logo, a compreensão de afetividade em relação ao professor revalida um sentimento de atitude de um estado de ação.

A aula é um momento mágico. Nela o professor se transforma pedagogicamente pelos processos cognoscentes na sua ação prática enquanto conteúdo a ser consumido. Todavia o educador não pode preparar o educando para resolver todas as atividades que constituem sua vida e sim ao longo de sua caminhada ele constitui essa habilidade.

A história da educação afetiva relata uma jornada através da motivação para o aprendizado o que motiva as pessoas a aprender, como essa motivação pode ser provocada e usada até o ponto do processo de aprendizado em si e como aprendemos. O papel do professor no processo de aprendizado é o de mediador que mostra que os alunos podem moldar o sucesso observando seu próprio sucesso em áreas afins, ou como modelar seu sucesso espelhando-se nas realizações de outros e compreendendo como eles fizeram isso.

Pensamos melhor quando temos um contexto e então a capacidade de mantermos o aprendizado e fazermos uso dele em qualquer outro contexto que 
acharmos apropriado. O contexto da educação afetiva e o desenvolvimento da Inteligência Emocional são muito bem descritos pelo conceito de Educação Convidativa (BREARLEY, 2004, p 80)

Não se deve esquecer que, além da importância da motivação para o aprendizado a afetividade foi um tema que por muito tempo não foi dado muita atenção pelos estudiosos da educação. Na História da Educação Brasileira as questões emocionais não eram temáticas vistas pelos educadores como importante para eles o importante era o cumprimento dos conteúdos.

Essa temática era vista pelos educadores como falta de interesse, os mesmos os quais mantinham um certo distanciamento dos alunos preocupando se apenas com o aprendizado com as notas que esses alunos tinham quer alcançar.

A partir da assertiva acima, é possível compreender que o autor destaca a importância do papel do professor no processo de aprendizado, exercendo um papel de mediação e ao mesmo tempo, ele serve de motivação para seus alunos. Quer dizer, torna-se um paradigma para que seus alunos percebam que podem alcançar o sucesso em "áreas afins", bem como realizar seus objetivos, tendo o estudo como base e olhando como exemplo o sucesso do próprio professor e das outras pessoas e como elas fizeram para alcançá-lo.

Isto acontece dentro do contexto da educação afetiva, ou seja, na vivência afetiva de forma respeitosa, a qual supõe interação entre o professor e seus alunos em sala de aula bem como em todo o contexto escolar.

\section{A Afetividade no Ambiente Educacional}

A aula pode ser um momento mágico, momento lúdico, momento de troca e socialização de saberes. Nesse espaço de interação, o professor se transforma pedagogicamente pelos processos cognoscentes na sua ação prática enquanto conteúdo a ser consumido. Desse modo, o professor na sua ação, na sua prática docente pode agir em sala de aula proferindo diálogo com seus alunos. Com isso, o professor estabelece uma relação de boa convivência com o alunado, haja vista a escola é responsável pela aprendizagem e deve fortalecer e desenvolver a direção, a orientação, as aptidões de perceber e raciocinar. 
O desenvolvimento dos conhecimentos é valioso para o aprendizado do indivíduo na sociedade de modo que este construa habilidades necessárias para resolver seus conflitos sociais. Mais do que saber respostas para questões, o aluno deve ser incentivado ao exercício da produção do seu próprio pensamento, que o torna apto a enfrentar as questões que aparecerão no decorrer de sua vida focando em objetivos que se baseiam-se em valores. Valores esses que levam o professor a ser capaz de redimensionar sua prática.

Os psicólogos quase sempre percebem a afetividade como parte da vida psíquica do ser, contudo, é incontestável reconhecer a importância do afeto para o bom funcionamento da inteligência. Pode-se afirmar então, que derrubar barreiras desnecessárias e inserir o estudante no contexto social da sala talvez seja um grande auxílio que está faltando para a eficácia no ensino aprendizagem (PIAGET, 1977).

Alguns educadores reagem com atitude autoritária que chegam a se comportar como repressores frente a alguma brincadeira de um aluno. Práticas como estas revelam que a grande maioria dos profissionais em educação ainda não consegue propagar uma situação de igualdade em sala de aula, tornando-se um ser superior a quem o aluno deve um respeito incondicional, sendo censurado todo e qualquer ato que deixe margem a uma interpretação de desrespeito à autoridade máxima da sala de aula precisamos de gente forte na educação, que esteja disposto a se levantar e dizer: "isto é hipocrisia não vamos mais fazer isso" (BUSCAGLIA, 1995)

A inserção do quesito afetividade no ambiente educacional pode beneficiar de forma significativa o processo de aprendizagem onde o educador poderá se transformar em um multiplicador dessa postura afetiva podendo levar para o ambiente doméstico muito do que se aprende na escola, beneficiando assim o convívio entre os familiares, sobretudo quando este é marcado pela desobediência e pelo desrespeito e falta de amor.

Se a criança consegue viver onde predomina o amor, muito do que ela aprender na escola poderá levar para sua casa, para os membros da sua família. Sendo assim, a aprendizagem é reconhecida como algo global, que não se limita à escola, vai acontecendo sempre enquanto a vida é percebida. Mesmo porque o indivíduo é um ser que está sempre em construção nunca acabado. 
Assim como a afetividade, a cognição é um elemento fundamental na psicogênese da pessoa completa, sendo o seu desenvolvimento também relacionado às bases biológicas e suas constantes interações com o meio. De maneira que é importante visualizá-los em constante interação quando do surgimento da inteligência. Refletindo sobre as origens orgânicas da inteligência.

\section{Afetividade e Aprendizagem}

O estado emocional do professor também deve ser levado em conta quando se estabelece que o educador esteja sempre pronto para atender o aluno demonstrado firmeza e equilíbrio emocional como se o único a ser envolvido nas relações emocionais fosse o aluno. Nesse caso, faz-se necessário que se estabeleça a relação entre professor- aluno e aluno- professor e aluno- aluno, pois todos os envolvidos no processo de ensino aprendizagem são dotados das mesmas capacidades emocionais.

Se algo que vivenciamos está sendo prazeroso, agradável, angustiante, causa medo ou pânico ou nos dá satisfação todos esses conceitos são atribuídos pela atenção que é impulsionada pela expressão das emoções e dos sentimentos e desenvolveu-se por meio da formação do sujeito. A benevolência é a parte do nosso psíquico responsável pelo medo de sentir e analisar a realidade. A afetividade é a parte psíquica responsável pela a organização dos sentimentos e de tudo que foi vivido e também é responsável pelas lembranças boas ou más.

Conforme Saltini (1999), mais do que saber respostas para questões o aluno deve ser incentivado ao exercício da produção do seu próprio pensamento, que os torna apto a enfrentar as questões que aparecerão no decorrer de sua vida. Não se trata de ensiná-los, mas, de prepará-los para enfrentar os desafios da vida futura.

Dessa forma a relação professor-aluno pode ser conflituoso, pois as diferenças sociais e culturais com diferentes objetivos baseiam-se em valores. Valores esses que levam o professor a ser capaz de redimensionar sua prática de forma que essas diferenças não venham interferir no convívio harmonioso dentro da sala de aula.

Vygotsky (2002) defende que a afetividade se manifesta na relação professor aluno e constitui elementos inseparáveis do processo de construção do conhecimento. 
Além da mais qualidade da intervenção pedagógica vai conferir um sentido afetivo para o objeto de conhecimento se fortaleça a partir das experiências.

Diante da assertiva acima, o docente pode ter a certeza de que, o dia a dia da sala de aula será mais produtivo em termos de aprendizado do seu alunado, em termos de aquisição de conhecimento e de estabelecimentos de laços sinceros de amizade com o professor e seus alunos e entre estes e seus coleguinhas, se a vivência da afetividade na relação professor-aluno for contemplada dada a sua importância vital, como deixam claro os autores supracitados, destacando que, de fato, estes elementos não podem ser separados do processo de construção do conhecimento.

É possível perceber como exemplo prático no cotidiano em sala de aula, que a aprendizagem dos alunos se torna mais efetiva eficaz quando existe a vivência da afetividade entre o professor e seus alunos, havendo interação, escuta, partilha das dificuldades escolares e até mesmo familiares, como não raro, ocorrem nas escolas.

Além do mais, outro exemplo, é a existência da afetividade na Educação Infantil, considerando que a criança está numa fase de rompimento com o ambiente familiar, para adentrar num novo ambiente ou seja, em outro meio social, o escolar, no qual serão necessários o afeto e a atenção dos professores e demais membros da comunidade escolar na formação de seus valores sociais, morais, culturais e educacionais.

Daí a importância de numa vivência afetiva, de que o professor saiba ter a sensibilidade de entender as necessidades e respeitar as dificuldades do alunado, como também a maturidade e nível de aprendizagem de cada um, motivando e despertando em todos o interesse pela aprendizagem.

As relações afetivas devem começar a ser construída entre professor e aluno no primeiro contato pedagógico. Para que esse clima se estabeleça de forma harmoniosa no dia, dia em sala de aula é imprescindível que se construa um elo de ligação em entre professor e aluno que é fundamental para a efetivação do processo de aprendizagem. Quando o aluno se relaciona bem com seu professor esse aluno absorve melhor o conteúdo que lhe é proposto 
Entretanto, vale a pena lembrar que a afetividade é uma das causas mais difíceis de se resolver no campo do estudo do comportamento do ser. Afetividade é a definição do que realmente significa o termo até porque muitos educadores entendem que o seu papel em relação aos alunos é de ensiná-los não de mimá-los. Observa-se, então, que o afeto se relaciona com sentimentos de ternura, amor, carinho e simpatia sentimentos que absorvemos desde pequenos.

Diante da importância que possui a afetividade, o afeto, as emoções nas relações humanas e no processo de aprendizagem, é preciso lembrar que:

\begin{abstract}
Vivemos uma cultura que desvaloriza as emoções em função de uma supervalorização da razão, num desejo de dizer que nós, os humanos, nos distinguimos dos outros animais por sermos seres racionais. Mas acontece que somos mamíferos e, como tais, somos animais que vivem na emoção. As emoções não são algo que obscurece o entendimento, não são restrições da razão: as emoções são dinâmicas corporais que especificam os domínios de ação em que nos movemos. Uma mudança emocional implica uma mudança de domínio de ação. Nada nos ocorre, nada fazemos que não esteja definido como uma ação de um certo tipo por uma emoção que a torna possível (MATURANA, 1998, p.92).
\end{abstract}

O autor enfatiza que vivemos em uma cultura que não valoriza a questão emocional, destacando, portanto, a importância das emoções como parte do ser humano integral, a fim de que este seja capaz de reconhecer suas próprias emoções e ao mesmo tempo também reconhecer as emoções do outro, com a finalidade de se estabelecer um diálogo mais democrático e menos conflituoso com seu semelhante, lembrando que essa temática nunca foi foco de discussão nas reuniões e jornadas pedagógicas até porque não faz parte da matriz curricular oficial.

Não obstante esta desvalorização das emoções, do afeto no âmbito do processo de aprendizagem, estes possuem grande importância, não devendo ser menosprezado pelos educadores e demais profissionais da educação.

O afeto, por sua vez, significa afeição; amizade; amor e designa um estado da alma, um sentimento; é uma mudança ou modificação que ocorre simultaneamente no corpo e na mente de alguém. A maneira como somos afetados pode diminuir ou aumentar a nossa vontade de agir.

Vale a pena lembrar que, além de Piaget, Wallon (1968) destacou a afetividade como sendo um dos aspectos centrais e mais importante para o desenvolvimento da criança. Ele ressalta que a interação e o estimulo é a base para uma aprendizagem 
bem-sucedida. Pontua a importância de uma relação sadia abrindo portas para o ser humano aprender.

Pode-se compreender, portanto, que sem a afetividade, o desenvolvimento, a aprendizagem da criança e seu processo de educação ficam comprometidos. Este processo educativo depende também da ação direta e afetuosa do educador e da forma como este age em sala de aula com seus alunos, pois, afirma "qualquer atitude do professor influencia o aluno, para o bem ou para o mal" (MORALES, 2009)

Desta forma, é importante que o professor estabeleça uma convivência harmoniosa com seu aluno para que este aluno se sinta acolhido e perceba que é importante naquele espaço escolar, ele seja capaz estreitar as relações para potenciar as habilidades de aprendizagem, mas também para construir um espaço onde as relações se deem de forma deleitável.

Por sua vez, Leite (2006) afirma que o atraso da Psicologia em reconhecer o papel da emoção e da afetividade no processo de ensino-aprendizagem, deve-se a hegemônica concepção cindindo do pensamento ocidental (concepção dualista do ser humano), onde a razão predomina sobre a emoção. Muitos discentes tiveram o intelecto bloqueado por motivos afetivos; outros há cuja afetividade não resolveu determinados problemas, apresentando lacunas ao longo do processo de aprendizagem.

Araújo (1995) conclui que a interação com o educador pode transformar a dificuldade de aprendizagem em melhores resultados escolares. Atualmente afetividade é considerada por diversos estudiosos como fundamental na relação educativa por conceber um clima propício a construção do conhecimento das pessoas em formação.

O estudante precisa se sentir parte do processo de construção do conhecimento afinal ele é a figura fundamental da construção dos saberes. Saberes esses que precisam vim encharcados de emoções para que a aprendizagem aconteça.

\section{Considerações Finais}


A afetividade está relacionada aos mais diversos termos: emoção, estados de humor, motivação, sentimento, paixão, atenção, personalidade, temperamento e outros tantos. Todas essas definições que muitas vezes são confundidas com emoção. A afetividade também exerce um papel importantíssimo em todas as relações, além de influenciar decisivamente a percepção, o sentimento, a memória, a autoestima, o pensamento, a vontade e as ações, sendo assim, é um componente essencial da harmonia e do equilíbrio da personalidade humana.

As condições afetivas fundamentais são as emoções, os sentimentos e as paixões. A palavra emoção vem do latim "moverem", mover-se para fora, eternizar-se. A emoção pode ser definida como um estado de ânimo que se manifesta de diversas formas em que o indivíduo de encontra.

É sabido que a carência afetiva prejudica o sujeito, principalmente o jovem que, até por conta da impulsividade própria da idade, tende a arriscar-se de forma temerária já que Ihe faltam boas e construtivas referências. $O$ afeto é considerado também o laço criado entre seres do mesmo sexo com uma amizade mais aprofundada. Afeição (vinda de afeto), é retratado como um apego a alguém, o que gera confiança, saudade, carinho e intimidade, um vínculo perfeito entre duas pessoas. $O$ afeto é um dos sentimentos que mais gera autoestima entre pessoas

Cientes de que afetividade e aprendizagem estão ligadas necessariamente, a fim de o processo de ensino-aprendizagem dos alunos seja profícuo e duradouro, no qual estes poderão agir como pessoas de bom caráter. No contexto educacional, a vida afetiva não pode ser dissociada do processo de cognição, pois as junções desses dois elementos são essenciais para a construção da aprendizagem.

Com efeito, considerando que a escola é, inexoravelmente, um ambiente de convivência e cidadania é preciso que ela possa trazer no seu alicerce o ideal de proporcionar aos alunos momentos significativos de afetividade, por este motivo a grande relevância dessa afetividade entre educadores e educandos no âmbito escolar. Logo o processo da relação afetiva pode ser benéfico quando professor e aluno buscam conhecimentos mútuos de suas necessidades, tendo consciência de sua forma de se-relacionar, respeitando as diferenças.

\section{Referências:}


ANTUNES, C. Professores e professauros: reflexões sobre a aula e práticas pedagógicas diversas. Petrópolis, RJ: Vozes, 2007.

ARAÚJO, C.M.M. Relações interpessoais professor-aluno: uma nova abordagem na compreensão das dificuldades de aprendizagem. Dissertação de Mestrado não publicada, Universidade de Brasília, Brasília,1995.

ARROYO, M. Ofício de Mestre: imagens e autoimagens. Petrópolis, RJ: Vozes. 2000.

BRASIL. Secretaria de Educação Fundamental. Parâmetros curriculares nacionais: introdução aos parâmetros curriculares. Secretaria de Educação fundamental. Brasília: MEC/SEF, 1997.

BREARLEY, M. Inteligência Emocional na sala de aula. São Paulo: Madras, 2004.

BUSCAGLA L. Vivendo e Aprendendo. São Paulo: RECORD, 1995.

CURY, A. Pais brilhantes e professores fascinantes. Rio de Janeiro: Sextante. 2003

FREIRE, J. B. Educação de corpo inteiro: teoria e prática da Educação Física. São Paulo: Scipione, 2001.

GADOTTI, M. História das ideias pedagógicas. 7. ed. São Paulo: Editora Ática, 1999.

GIMENO SACRISTÁN, J. Poderes instáveis em educação. Porto Alegre: ARTMED Sul, 1999.

LEITE, S.A.S. (org.). Afetividade e práticas pedagógicas. São Paulo: Casa do psicólogo, 2006.

LIBÂNEO, J. C.; OLIVEIRA, J.. \& TOSCHI M.S. Educação escolar: políticas, estrutura e organização. 2a ed. São Paulo: Cortez, 2005

MATURANA, H. Emoções e Linguagem na Educação e na Política. Belo Horizonte: UFMG, 1998

MORALES, P. A relação professor-aluno: o que é e o que faz. São Paulo: Edições Loyola, 2009.

NERES, A.P.F. Tendências pedagógicas na escola atual. Saber na Rede Portal de disseminação do conhecimento, 23/02/2011. Disponível em: https://www.sabernarede.com.br/tendencias-pedagogicas-na-escola-atual/. Acesso em 19 abr. 2020

NÓVOA, A. O passado e o presente dos professores. In: NÓVOA, António. Profissão Professor. Por NÓVOA, A. (1995). [s.l.]:Porto Editora,1995.

PIAGET, J.; INHELDER, B. A Psicologia da Criança. Trad. Octavio M. Cajado. São Paulo: Difel, 1968 
PIAGET, J. A formação do simbolismo da criança. Rio de Janeiro: Zahar, 1975.

PIAGET, J. O desenvolvimento do pensamento: equilibrarão das estruturas cognitivas. Lisboa: Dom Quixote, 1977.

PIAGET, J. et al. Abstração reflexionante. Relações lógico-elementares e ordem das relações espaciais. Porto Alegre: Artes Médicas, 1995.

PIMENTA, S.G. Professor reflexivo: construindo uma crítica. In: PIMENTA, S. G.; GHEDIN, E. (Orgs.). Professor ref. Professor reflexivo no Brasil lexivo no Brasil: lexivo no Brasil gênese e crítica de um conceito. São Paulo: Cortez, 2002.

SALTINI, C. J. P.. Afetividade e inteligência: a emoção na educação. Rio de Janeiro: DP\&A, 1999.

VYGOTSKY, L. S. Pensamento e Linguagem. São Paulo: Martins Fontes, 1993.

VYGOTSKY, L. S. Uma Perspectiva Histórico Cultural da Educação. Rio de Janeiro: Ed. Vozes, 2002.

WALLON, H. A evolução psicológica da criança. Lisboa: Edições 70, 1968

WALLON, H. Do ato ao pensamento. Lisboa: Moraes Editores, 1978

WALLON, H. A evolução psicológica da criança. Lisboa: Edições 70, 1999.

WALLON, H. Do ato ao pensamento: ensaio de psicologia comparada. Petrópolis, Rio de Janeiro: Vozes, 2008. 